\title{
Public Low-Cost Housing Design: The Residents' Perception
}

\author{
Sunusi Bashari, Ahmad Hariza Hashim, Asnarulkhadi Abu Samah, Nobaya Ahmad
}

\begin{abstract}
The purpose of this paper is to explore the design of public low-cost housing in Jigawa State, Nigeria and assess how residents perceived the housing units in relation to their culture and impact on their well-being. The housing units were constructed as an intervention by the government for low-income earners. This research was conducted through both qualitative and quantitative approaches. In qualitative aspect, three respondents were interviewed to express their perception on the public low-cost housing design, while quantitative aspect assessed the residential housing attributes of low-cost housing estates with view to identify the important housing attributes considered by the residents for their well-being and was used to support the qualitative aspect. This was achieved through descriptive statistics using Relative Importance Index (RII). A well-structured questionnaire was administered to the residents of public low-cost housing of Jigawa state, Nigeria. The results indicated that, the design of public low-cost housing in Jigawa State, Nigeria does not reflect the culture of the residents, most of the residents were not satisfied with it. In addition, out of fifty five (55) constructs from five (5) housing-related dimensions, the result identified thirty two (32) important attributes out of these, the residents considered twelve (12) to be the most important attributes affecting their well-being. Thus, the paper would serve as a blueprinted government, housing policy makers and housing developers to understand that, the housing constructions and infrastructural elements should reflect the cultural background of the beneficiaries. Views of beneficiaries before and after construction of public low-cost housing are of great importance. The findings of this paper were based on reviewed of earlier studies on residential-housing units, field work and research conducted on particularly the public low-cost housing in Jigawa State, Nigeria
\end{abstract}

Keywords: Culture, Low-cost housing, Residents' perception, Well-being

\section{INTRODUCTION}

Housing is regarded as one of the basic needs of mankind providing not only shelter but also private and dynamic setting for social activities and interactions [9]. Alaghbari, Salim, Dola, and Abdullah Abang Ali [3] viewed housing as a

Revised Manuscript Received on September 22, 2019.

* Correspondence Author

Sunusi Bashari*, Department of Geography, Jigawa State College of Education, Gumel, Jigawa State, Nigeria. Email:sunusibashari6@gmail.com

Ahmad Hariza Hashim, Department of Resource Management and Consumer Studies, Faculty of Human Ecology, University Putra Malaysia. Email: ahariza@upm.edu.my

Asnarulkhadi Abu Samah, Department of Social and Development Sciences, Faculty of Human Ecology, University Putra Malaysia. Email: asnarul@upm.edu.my

Nobaya BT Ahmad, Department of Social and Development Sciences, Faculty of Human Ecology, University Putra Malaysia.

Email: nobaya@upm.edu.my factor which is well known to be very important in human life and plays role in both social and economic aspects on the total living environment of the world. Alaghbari et al. [3] viewed housing as a factor which is well known to be very important in human life and plays role in both social and economic aspects on the total living environment of the world. Majority of low-income earners in Nigeria live in poor quality and substandard housing because access to quality housing is far beyond the economic reach of the most of the citizen [23].

In Nigeria, statistics has shown that over 7 out of every 10 people live below the minimum poverty level and 9 of every 10 are in the low-income group [11]. This indicates that, these people cannot provide housing for themselves, they need intervention from government through public low-cost housing. Public Low-cost housing has been defined as constructed public residential houses funded by the government or in partnership with the government under the public-private partnership (PPP) scheme, to provide affordable housing for low-income people [5], [23]. According to Olotuah [33] several interventions by government in Nigeria failed because, firstly the Government lack vital information on residents as such it has a wrong perception of the need of low-income earners which results in the provision of inadequate and wrong kinds of housing and aids for them, secondly there has been improper planning and poor execution of housing policies and programs. These programs, aside from direct house construction of low-cost houses by the Federal Government, are not directed at low-income earners and lastly, Government has always provided very few number of houses which are nonetheless too expensive for low income earners, most of the residents dissatisfied with the design and are taken over by the affluent in the society.

\section{LiteratURE REVIEW}

There are important information that need to be gathered on socio-cultural aspects of the beneficiaries before construction of public housing schemes and after the construction certain information are also vital in giving supporting evidence which can be used to judge the performance of public housing schemes [15], [23]. Delgado \& Troyer [10] observed that, in any housing projects apart from financial investment, users' need and preferences must be considered for a successful housing projects for low-income earners. Architects and planners in housing can only provide adequate housing if users' needs and preferences are well understood. Jansen [18] described residential preference as relative attractiveness to house by individual. This concept of 
preference became an important issue in housing studies because it gives clear image of households' priority for particular housing attributes. Thus, understanding the preference of housing will help in making housing policy and framework for future housing environment especially housing for the poor [19].

Turner [42] described the failure of housing programs in most of developing countries like Nigeria as a result of adopting and maintaining the minimum standard of housing introduced since 1915 from Western World and neglecting priority as well as needs of users in formulating housing programs. The minimum standard of housing outlined that; there should be a separate bedroom, an equipped bathroom and a kitchen should be separated from living area. In contrast, traditionally, in Nigerian culture, the household slept according to age and sex. When the children were young, they slept in the same enclosure as their parents. As they reached puberty, the parents built special enclosures with the men often having their own individual space and the women staying together. These units were separated and in different parts of the yard, given each a great sense of privacy [24]. In addition, the typical 'modern' three-bedroomed house all the bedrooms are located together. The negative comments in these homes often focused on the bedrooms and their proximity (resulting lack of privacy) or that the master bedroom was not large enough to allow smaller children to sleep there as well [41]. This design is against the culture and traditions of Nigerians, because there is a strong relationship between culture and environmental design as such cultural differences must be considered in design procedure and identification of environmental effects on people living in a particular environment [37].

Linton [21] defined Culture as a complete way of life of any society. Generally, Muslims living in different countries are influenced by cultural factors that function in their respective country of residence. Cultural factors assist in shaping the architectural use of space and styles within Muslims houses in several ways [34]. Rapoport [36] viewed components of culture should comprises of worldviews (expectations, standards, values, norms, rules and meanings), social network, kinship and kinship relations, and family structure. Rapoport [36] confirmed that these components have influence in shaping or forming the built environment. Design of the built environment is the association of four things: communication, space, meaning and time. Then, it becomes necessary to consider, investigate and discuss the implication of each for a given culture. One may find space organization (and form) is more important, while other may take shape is more important as in the case of identity, religion etc. as such to be specific become necessary whether about culture or the environment.

However, few studies focused on the role of natural environment in people's self-assessments of life satisfaction. Jabareen [17] findings in the study of culture and housing preferences in developing city revealed housing preferences in Gaza are determined by components of culture such as social relations, religions, kinship, gender and politics. The conclusions was that among the cultural components, attitudes and kinship relations toward women are possibly to be the most important for individual Palestinians seeking new housing. Houses reflect culture, whether through everyday uses or purposeful design. House forms, such as their interior layouts, and the dwellings layout in a neighborhood can be supportive or disrupting of the culture of their inhabitants [17].

Most of low-cost housing estates are usually of low standard and in most cases the housing design does not addresses the socio-cultural lifestyle of the low income groups in Abuja, Nigeria [29]. Olayiwola, Adeleye \& Jiboye [32] in their research the effect of socio-cultural variables on housing quality in Oshogbo, Nigeria, they found out that, the level of quality building and elements such as design, building space, drainage system are below the desired and expected standard in the study area. This may be attributed due to negligence of some aspect of culture in the housing design. Understanding of the multi factorial nature of the influences on the Muslim perception on the housing unit and the use of space is very important for building designers, architects, engineers and builders to be effectively equipped to meet the needs and aspirations of the beneficiaries [34]. In this regard, majority of people in Jigawa state are Muslims, they value privacy in their housing setting especially when one refer back to their traditional housing.

Fadairo \& Olotuah [11] studied public low-cost housing for urban poor focusing on materials and techniques of construction in Lagos State, Nigeria and their findings showed that, the low-income earners can solved the problem of high cost of building materials encountered by adapting the use of locally available materials and building construction techniques. Eziyi Offia Ibem, Aduwo, and Uwakonye [14] concentrated their research on adequacy of incremental construction for housing low-income urban residents in Ogun State, Nigeria, their findings showed that housing environment in the housing estate met the needs of the respondents in terms of provision of adequate housing unit characteristics much higher than social infrastructure, housing services and management of the housing estate. This means that, the residents need much on social infrastructure, housing services and improvement in estate management.

In their research, Mohit and Iyanda [27] revealed that residents of public low-cost housing in Niger State, Nigeria, indicated low satisfaction with safety situation, neighborhood facilities and social interaction among the residents, more especially security challenges at night as well as inadequate schools and hospitals around the housing estates. Assessment of the quality of life of Benin City, Nigeria conducted by Olajuyigbe, Osakpolor, and Adegboyega [31] revealed that, there is need to improve social, physical and economical aspects of life of the inhabitants through provision of basic amenities. Asiyanbola, Raji, and Shaibu [4] stated that most of public essential facilities and social amenities were not in good conditions to support human well-being at Ago-Iwoye and Ijebu-Igbo housing estates, both located in Ogun State, Nigeria.

Therefore, based on literature review, The expectation of people on residential housing attributes varies with socio-demographic parameters which affect the ways through which neighbors interact with others and determine how they use shared outdoor spaces [20], [35]. This means apart from socio-demographic factors, cultural factors also influences people expectations,

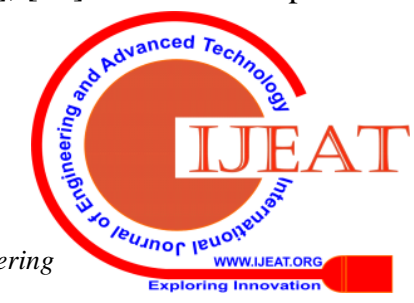


preferences, and aspirations regarding residential livability. This is confirmed by Rapoport [37] who listed five factors that have strong influence on the built form; these are social interaction, family, basic needs, privacy and position of women. In addition, Rapoport [37] stressed that these factors could be used as a tool to design the organization of a house or a whole neighborhood that comprises the interaction between the dwelling and public spaces. However, none of these studies focuses on public low-cost housing design in relation to the perception of residents in Jigawa State, what housing attributes do residents considered most important based on their culture. This research tends to bridge the gap in literature by exploring public low-cost housing design: residents' perception and determine the most important attributes considered by the residents.

\section{METHODOLOGY AND MATERIALS}

This research employed both qualitative and quantitative methods. First, the research focuses on the qualitative dominant approach to confirm qualitative research results through quantitative method. In the literature review, residents of public low-cost housing estates in Jigawa State do faced with a lot of problems and the housing scheme provided has unanticipated effects on the residents' well-being. Therefore, there is need to identify how residents perceived residential public low-cost housing attributes, which only qualitative aspect of the research can give the details. In this research phase, qualitative design was preferred through case study method. The choice of qualitative method was as a result of the issue at stake is perception on certain elements of housing which is more of interactive process, understanding it, require suitable qualitative rather than quantitative method [16]. Questions such as "why" and "how" were asked so as to tap information on the issue under investigation.

Ritchie and Lewis [38] stated, purposive sampling is often used for selecting a sample in most of qualitative research. Here, the respondents were purposely selected to represent the particular features of a group within the sampled population, among the features were; they are adult, head of the family, civil servant which make them appropriate for small scale, but better understanding and in-depth exploration of the phenomenon that the researcher intended to study [38]. Thus, in this study, three respondents were purposely selected through snow-balling and were all residents of public low-cost estates in Jigawa state, Nigeria. Moreover, quantitative research aspect was employed to identify the most important residential housing attributes considered by the residents of public low-cost housing in Jigawa State. The researcher chose to use survey research design by using questionnaire for the data collection, whereby a sample of population was obtained through multi-stage cluster sampling, such as simple random sampling, proportionate random sampling and systematic sampling. One hundred (100) housing units were randomly selected across the three sample public low-cost housing estates in the study area and administered 100 questionnaire of which 92 were returned which marked the $92 \%$. The respondents were asked to assess the fifty five (55) constructs of the five (5) residential housing-related attributes for perception of public low-cost housing through 7-point Likert scale (of 1=not important; 2=low importance; 3=slightly important; 4=neutral; 5=important; 6=very important; 7=most important). Then thereafter, data analysis with descriptive and inferential statistics particularly Relative Importance Index (RII) was used to identify what residents of public low-cost housing considered the most important among the residential housing-related attributes.

\section{RESULTS, FINDINGS AND DISCUSSIONS}

\section{A. Qualitative Aspect}

\section{Public Low-Cost Housing Design}

Generally, there are two types of public low-cost housing estates in Jigawa State, one bed-room and two bed-room, their designs differed. For instance, one bed-room housing estate include 744 housing estate and some housing units at Fatara housing estates. While two bed-room housing estates are; Yadi and Red-Bricks housing estates. The researcher conducted an interview with respondents as follows;

Informant 1, described the housing design of 744 housing estate as just a one bed-room and a parlor, toilet and kitchen; The design of 744 low-cost housing estate, is only one bedroom and a parlor, toilet and kitchen.

Informant 2, further explained other additional information on the housing design of 744 housing estate as follow;

The 744 housing estate do not have fence. Most of facilities provided are shared among all the houses. For example, toilet system (all houses are connected with single main pipe), common roofing ceiling and party wall.

In another perspective, the two bed-room housing design are almost similar in nature especially Takur and Yadi housing estates. Informant 3 , has the following description of the two estates;

The design of Yadi housing estate is 10 housing units per 1 block, the houses are fenced. There is covered space which is used as main entrance/gate called "Zaure". There are two bedrooms, toilet, bathroom, and kitchen and court yard in each housing unit.

Research finding revealed the general housing design of all public low-cost housing estates in Jigawa State, have either one or two bed-room housing unit, toilet and sometimes bathroom separated from toilet, main door/entrance, windows, party wall (open spaces above ceiling level across all the housing units), close proximity of two bed-room's doors, verandah, open court yard and shared facilities like toilets system, ceiling roofing and wall boundary. This design is similar to what Noriza [30] described as standard design. According to her, this design of housing unit described mainly the interior aspects of the dwelling unit such as size of the house, size of the living area, location of other attributes like toilet and kitchen. Meanwhile, Mohit and Al-Khanbashi Raja [25] in their description of formal attributes of dwelling unit they pointed out the physical characteristics of housing unit as the size of the living area, washing area, laundry and kitchen space. Housing unit expected to consist certain attributes like number of bedrooms and bathrooms, level of sockets, aspects of housing such as housing quality, privacy, housing services provided by developers like ventilation of the house, brightness, garbage disposal and safety [40]. However, low-cost housing are said to be the housing unit that consist just the basic features as explained by some of the housing officials in Jigawa State. As stated 
earlier, Jigawa State people are predominantly Muslims, the design of traditional Muslim house is based on certain guidelines from principles prescribed by Islamic Sharia obtained from the Quran (revelations of Allah to Prophet Muhammad) and Hadiths (utterances and actions of Prophet Muhammad) [34]. Residents explained their perception with regard to relationship between housing design and privacy.

\section{Housing Design and Privacy}

Residents were asked how they will relate the housing designs with their privacy in the respective housing estates, the researcher wanted to know whether the housing design ensure privacy based on their understanding with the term "privacy". Informant 1 , the resident of 744 housing estate explained the design of the housing unit in relation to his privacy in the house;

The design of this low-cost housing estate, there is nothing like privacy, because, the design of this housing unit is only one bedroom and a parlor, which to me the design is for only for one person for life, if I can relate the housing unit to my culture. In Nigerian culture, where ever you are working, you tend to go with your family (wife/husband), as the time goes on, the family will increase in number (having children), so as Muslims, we need privacy and my culture require separation of children based on sex and age. You see, this housing unit is only one bedroom and a parlor, as such the design does not guarantee privacy especially for a family man having wife and children.

Informant 2, added his experience as a resident for over 15 years in 744 housing estate;

Actually the design of this housing estate do not ensure privacy, because there is no fence. If you are living in a housing unit at times like you are living at outside room, because people from outside can see you. Most of facilities provided are shared among all the houses. For example, toilet system (all houses are connected with single main pipe) and common roofing ceiling, so whatever happen to your neighbor may affect you as well. No privacy at all.

Contrary, to the views of informants 1 and 2, according to the informant 3, the housing design of Yadi housing estate, addresses the culture and privacy of Hausa ethnic group especially in the structure like fencing and "Zaure" (roofed entrance). To him, apart from sharing of common facilities and proximity of the doors of the two rooms, the housing design ensure privacy;

In this housing unit, the housing design include, Main entrance, two bedrooms, toilet, bathroom and kitchen. The design does not allow direct view from outside the house to the interior except through main entrance if opened, few spaces can be viewed like courtyard, but there is wall fencing, this main entrance is roofed and used to receive strangers. Apart from this, other places like kitchen, toilet, bath room, bedrooms etc. cannot be viewed even if main entrance is opened. These are some of the design attributes that address privacy in Hausa Culture.

Residents were asked whether the housing design of their respective housing estates ensure privacy or there were need to improve the design. The result of this aspect indicated that, generally, the housing design of all public low-cost housing estates in Jigawa State does not ensure privacy to the residents of the estates. Considering the design of the housing unit in relation to the culture of Jigawa State people where they value privacy as the most important aspect in their life style. For instance, apart from Takur and Yadi housing estates, all housing units within all public low-cost housing estates have no fence or wall demarcation. This fence or wall demarcation provide maximum privacy as encouraged by Hausa/Muslims' culture. Larger family is part of the culture of the Jigawa State people, present one or two bed-room housing unit is not what residents wants and is not recommended for the larger family. Also, there were limited number of toilets and bathrooms which in most of the houses the toilet system are shared among the neighbors. Noriza [30] marked these features such as number of bed-rooms, size, and location of kitchen as relevant to resident's well-being. Little or absent of theses affects general well-being of the residents. Li, Sun \& Jones [20] in their study, found out that, some residents preferred to live in three-bedroom dwelling units not one or two bedroom design. Similarly, in their findings, the study of Mohit and Iyanda [26] in Nigeria, indicated that, although the respondents are living in two and three bedrooms, but they preferred four bedroom. In addition, the size of windows at Takur, Yadi and 744 housing estates were either very small, limited in number, no cross ventilation or positioned at very low level to the ground which allowed children view from outside.

\section{Housing Design Attributes and Privacy}

Residents of these low-cost housing estates in Jigawa State, complained about certain housing design attributes which directly affect the privacy of their families. They mentioned position of the toilet, shared facilities and limited number of bed-rooms and windows to mention just a few were among the housing designs attributes that affect the privacy of their families. Informant 1 , had this to say;

Actually, the design of the toilet is not well designed, if a visitor or a stranger come to your house, he/she can easily sighted you while you are entering into the toilet, because, toilet is directly facing people who are sitting in the parlor. How long you stayed in the toilet can easily be estimated, which to me is not in line with our privacy and culture in general.

Informant 2, added comments on how the housing design attributes affect his family's privacy as follows:

Of course, the design attributes that affect my family's privacy are shared facilities, for instance, from house number one, through ceiling some body can pass all the remaining three houses no partitioning between houses beyond ceiling (party wall). Although, I have already demarcated (blocked party wall spaces) between my housing unit and my neighboring housing units. If not demarcated, whoever talk in his or her room, his or her neighbor will hear the voice from his or her own room, as such no privacy. But as long as you separated your housing unit by constructing wall to block the spaces between neighbors there will be no sound of discussions.

As usual, residents of Yadi housing estate, have different views with regards to housing design attributes in relation to

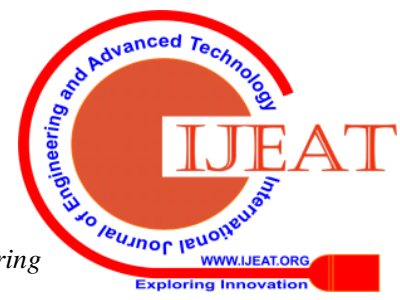


privacy of the families. Informant 3, emphasized that, his family were well protected none of the housing design attributes have negative impact on them, he explained;

Generally, if you consider the design of this housing unit, the design attribute does not affect my family's privacy as I have explained earlier. For example, the housing unit is fenced, if the main entrance is facing west direction, the two rooms are facing east direction, this means, even if the main entrance is open, those outside will not have direct view to the rooms, toilets and kitchen. The toilet/bathroom are facing towards south direction while the kitchen is facing towards north direction. In short, the design attributes has no any effect on my family's privacy at all.

Spatial and architectural elements such as bedrooms, doors and windows are not only functional features but also they employ substantial role on human domestic interactions and behavior within home environment [13]. This study revealed that, some of the housing designs attributes affect the family's visual privacy as explained by the residents during individual interview. Some of the respondents pointed out that, the designs of position and location of some attributes such as toilet, doors, windows were positioned and located in such as a way that family inside the house are exposed to the visitors, strangers and passerby. Visual privacy is the most important aspect of privacy which serve as the predominant design objective to ensure the safety and privacy of female members within Muslim houses [2]. This type of privacy can be achieved through several external designs interventions, such as the design and location of entrance doors, the sizes and placement of windows and openings, the control of building balconies and heights, and the including of internal court yard and gendered spaces [6], [12] and [28]. Although, there were need for more bedrooms because of the limited number of bed-rooms across all public low-cost housing in the state, but respondents have the opinion that, provision of more bed-rooms in the housing unit is not sufficient to provide privacy for the family in almost all the housing estates.

To ensure sufficient privacy, residents wanted the location and positioned of the main entrance/proximity of doors in two bed-rooms housing estates and windows to be adjusted to their culture. In addition, there should be fencing of the housing unit, provision of more toilets and bathrooms. This residents' perceptions is similar to the suggestions given by Bahammam [6], Bekleyen and Dalkiliç [8] and Mortada [28] that, the front of main entrance door is the most recognized demarcation between private and public realms. Main entrance doors in traditional Muslim houses are placed away from the main road/street and not directly facing the opposite neighbors.

\section{B. Quantitative Aspect}

In quantitative aspect, Relative Importance Index (RII) was used to determine most important public low-cost housing-related attributes for low-income people in jigawa State. Basiru, Yacob, Radam, and AbdManaf [7] described the use of Relative Importance Index in analysis as one of the best method using a ranking of multivariate correlation coefficient from high to low as the most helpful approach for ranking the relative importance attributes. Previous studies such as Lukuman, Sipan, Raji, and Aderemi [22], Tanko, Abdullah, and Ramly [39] and Adegoke [1] used RII on various studies.

Respondents (residents of public low-cost housing) were explored with 7 Likert scale so as to determine the relative importance index (RII) of the fifty five (55) constructs of the five (5) public low-cost housing dimensions for the assessment of the perception of the residents. The RII was explored using:

$$
\mathrm{RII}=\left(\sum \mathrm{W}\right) /(\mathrm{A} \times \mathrm{N})
$$

Whereas:

$\mathrm{W}$ - Represents weight given to each factor by the residents (1=not important to 7=most important).

A- Represents highest weight

$\mathrm{N}$ - Represents total number of residents responded.

A decision rule was adopted in determining the ranges for most important (MI) to not important (NI) using:

RII Decision Rule $=($ Max RII-Min RII $) / A$

The magnitude is weighted by the maximum value $(\mathrm{A})$ of the response category which depends on the rating scale adopted. Therefore, the rating index is expected to range between 0 and 1 irrespective of the scale. The interpretation is, the closer an attribute's score approaches 1, the higher is its perceived importance about others and vice-visa.

Table 1 indicated the residents' ranking of public low-cost housing attributes within and among the groups. The 1st most important attribute is neighbors' friendliness ( $\mathrm{RII}=0.859$ ), availability of Masjid (Mosque) attribute ranked 2nd the most important with RII (0.852) and 3rd most important attribute is accessibility to electricity/power supply (RII=0.849). The 4th most important attribute is trust to neighbors $(\mathrm{RII}=0.837), 5$ th most important attribute is number of toilets in the housing unit $(\mathrm{RII}=0.821)$. Meanwhile, both safety from crime and access to water supply ranked 6th the most important attributes each with (RII=0.82 each). (See table 1 ).

The findings of this study confirmed that each of the dimension selected were found to be the most important dimension in relation to public low-cost housing in Jigawa State. These include: social environment-related; physical environment-related; functional environment-related; dwelling unit features-related and safety and crime-related. This is because the top ten (10) most important public low-cost housing attributes distributed across these 5 dimensions. However, there were public low-cost housing attributes that residents ranked as very important to them, these include; size of the housing unit, number of bathroom, police protection, and distances to place of work, school and hospital. Furthermore, ventilations spaces, cleanliness of the drainage, noise level, community associations, distance to market, etc. have been ranked as important attributes by the residents (See table 2). 
Table 1: RII and ranking of public low-cost housing attributes

Dwelling unit

\section{Attribute}
\begin{tabular}{l|l|l|l|l}
$\mathbf{N I}$ & LI & SI & N & I \\
$(\mathbf{1})$ & $(\mathbf{2})$ & $(\mathbf{3})$ & $\mathbf{( 4 )}$ & $\mathbf{( 5 )}$
\end{tabular}

VI
$(6)$

MI
$(7)$

SUM

RII

RANK

RANK $\quad$ RANKING

\section{WITHIN}

The size of Housing unit

The size of Living area

The number of Bedroom

The size of Dinning area

The Ventilation spaces

The number of Toilet

The number of Bathroom

The size of Kitchen

The size of Drying area

DUF1

\begin{tabular}{|l|l|l|l|l|}
\hline 1 & 6 & 9 & 56 & 90 \\
\hline 1 & 12 & 51 & 64 & 90 \\
\hline
\end{tabular}

\begin{tabular}{l|l|l|l} 
& 168 & 175 & 505 \\
\hline & 114 & 105 & 437 \\
\hline & 174 & 203 & 526 \\
\hline 36 & 70 & 352 \\
\hline 5 & 96 & 161 & 465 \\
\hline 5 & 162 & 189 & 529 \\
\hline & 96 & 168 & 477 \\
\hline & 96 & 84 & 496 \\
\hline 72 & 182 & 440 \\
\hline
\end{tabular}

\begin{tabular}{|l|l}
\hline & 0.784 \\
\hline 0.679 \\
0.817 \\
0.547 \\
\hline 0.722 \\
\hline 0.821 \\
0.741 \\
\hline 0.615 \\
\hline 0.639 \\
\hline 0.683
\end{tabular}

\begin{tabular}{|l|l|l|l|l|l|l|} 
DUF10 & 8 & 8 & 36 & 64 & 70 & 72 \\
Social Environment
\end{tabular}

\begin{tabular}{l|l|l|l|l|l|l|l|l|l} 
DUF3 & 0 & 2 & 9 & 48 & 90 & 174 & 203 & 526 & 0.817 \\
\hline
\end{tabular}

\begin{tabular}{l|l|l|l|l|l|l|l|l|l|l} 
DUF4 & 17 & 14 & 33 & 92 & 90 & 36 & 70 & 352 & 0.547 \\
\hline
\end{tabular}

\begin{tabular}{l|l|l|l|l|l|l|l|l|l} 
DUF5 & 2 & 8 & 27 & 76 & 95 & 96 & 161 & 465 \\
\hline
\end{tabular}

\begin{tabular}{|l|l|l|l|l|l|l|l|l|} 
DUF6 & 0 & 2 & 3 & 28 & 145 & 162 & 189 & 529 \\
\hline
\end{tabular}

\begin{tabular}{|l|l|l|l|l|l|l|l|l|}
\hline DUF7 & 3 & 10 & 9 & 64 & 115 & 108 & 168 & 477 \\
\hline DUF8 & 10 & 12 & 36 & 80 & 85 & 96 & 77 & 396 \\
\hline
\end{tabular}

\begin{tabular}{|l|l|l|l|l|l|}
\hline DUF9 & 7 & 6 & 48 & 76 & 95 \\
\hline
\end{tabular}

The Cleanliness of the drainage

Noise level

Guard keeping you at night

Neighbors' friendliness?

Neighborhood helpful?

Trust your neighbors?

Community Association?

SE1

SE3

SE4

SE5

\begin{tabular}{r|l|l|l}
8 & 20 & 9 & 36 \\
6 & 14 & 21 & 44 \\
0 & 0 & 0 & 44 \\
2 & 4 & 15 & 32 \\
0 & 2 & 12 & 40 \\
\hline 5 & 14 & 39 & 64 \\
\hline
\end{tabular}

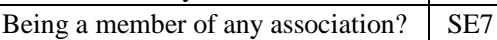

\begin{tabular}{|c|}
\hline \\
\hline Play area \\
\hline Parking area
\end{tabular}

Parking area

Masjid (Mosque)/ Church Perimeter road

Pedestrian Walkways

Work place

Police Station

Multipurpose hall

Local shops

Food Stalls

Motor park/bus stop

Library

Green Space

Market

\begin{tabular}{l|l|l|l|l} 
SE7 & 14 & 22 & 51 & 6 \\
\hline
\end{tabular}

\begin{tabular}{l|l|l|l|l}
36 & 105 & 132 & 133 & 443 \\
\hline
\end{tabular}

\begin{tabular}{|l|l|l|l|l|}
44 & 105 & 114 & 147 & 45 \\
\hline 44 & 90 & 132 & 287 & 553 \\
\hline 32 & 75 & 144 & 252 & 524 \\
\hline
\end{tabular}

\begin{tabular}{l|l|l|l|l}
32 & 75 & 144 & 266 & 539 \\
\hline 64 & 70 & 78 & 168 & 438
\end{tabular}

\begin{tabular}{l|l} 
& \\
\hline & 0.688 \\
\hline
\end{tabular}

\begin{tabular}{|l|l|l|}
$3^{\text {rd }}$ & $13^{\text {th }}$ & VI \\
\hline $7^{\text {th }}$ & $31^{\text {st }}$ & I \\
$2^{\text {nd }}$ & $8^{\text {th }}$ & MI \\
\hline $10^{\text {th }}$ & $49^{\text {th }}$ & SI \\
\hline $5^{\text {th }}$ & $24^{\text {th }}$ & I \\
\hline $1^{\text {st }}$ & $5^{\text {th }}$ & MI \\
$4^{\text {th }}$ & $20^{\text {th }}$ & VI \\
$9^{\text {th }}$ & $43^{\text {rd }}$ & N \\
\hline $8^{\text {th }}$ & $38^{\text {th }}$ & N \\
\hline $6^{\text {th }}$ & $29^{\text {th }}$ & I
\end{tabular}

\begin{tabular}{l|l}
64 & 70 \\
\hline 64 & 50
\end{tabular}

\section{Physical Environment}

\begin{tabular}{l|l|l}
112 & 361 & 0.68 \\
\hline 112 & 361 & 0.561
\end{tabular}

\begin{tabular}{|l|}
\hline 0.688 \\
\hline 0.7 \\
\hline 0.859 \\
0.814 \\
\hline 0.837 \\
\hline 0.68 \\
\hline 0.56
\end{tabular}

\begin{tabular}{|l|l|l}
\hline $5^{\text {th }}$ & $28^{\text {th }}$ & I \\
\hline $4^{\text {th }}$ & $27^{\text {th }}$ & I \\
\hline $1^{\text {st }}$ & $1^{\text {st }}$ & MI \\
$3^{\text {rd }}$ & $9^{\text {th }}$ & IM \\
\hline $2^{\text {nd }}$ & $4^{\text {th }}$ & MI \\
\hline $6^{\text {th }}$ & $30^{\text {th }}$ & I \\
\hline $7^{\text {th }}$ & $47^{\text {th }}$ & SI
\end{tabular}

\begin{tabular}{|l|l|l|l|l|}
\hline PE1 & 16 & 18 & 27 & 56 \\
\hline PE2 & 6 & 20 & 33 & 64 \\
\hline PE3 & 0 & 8 & 0 & 28 \\
PE4 & 7 & 30 & 54 & 40 \\
\hline PE5 & 7 & 28 & 45 & 96 \\
\hline PE6 & 0 & 4 & 12 & 64 \\
\hline PE7 & 5 & 6 & 9 & \\
PE8 & 17 & 30 & 75 & 76 \\
\hline PE9 & 2 & 14 & 57 & 88 \\
\hline PE10 & 7 & 16 & 60 & 64 \\
\hline PE11 & 1 & 6 & 12 & 60 \\
PE12 & 30 & 30 & 57 & 32 \\
\hline PE13 & 20 & 30 & 42 & 36 \\
\hline PE14 & 3 & 0 & 3 & 44 \\
\hline & & & &
\end{tabular}

\begin{tabular}{l|l|l|l|}
100 & 84 & 70 & 371 \\
\hline
\end{tabular}

\begin{tabular}{|l|l}
\hline & 0.576 \\
\hline & 0.643 \\
\hline & 0.852 \\
0.58 \\
\hline & 0.559 \\
\hline & 0.747 \\
\hline & 0.703 \\
\hline & 0.446 \\
\hline & 0.62 \\
\hline & 0.58 \\
\hline & 0.75 \\
& 0.40 \\
\hline & 0.498 \\
\hline & 0.783
\end{tabular}

\begin{tabular}{|l|l|l}
$10^{\text {th }}$ & $46^{\text {th }}$ & SI
\end{tabular}

SI

\begin{tabular}{l|l|l|l|l|}
64 & 90 & 96 & 105 & 414 \\
28 & 85 & 120 & 308 & 549
\end{tabular}

\begin{tabular}{l|l|l|l}
95 & 66 & 84 & 376
\end{tabular}

\begin{tabular}{|l|l|}
\hline 63 & 360 \\
\hline 112 & 481 \\
\hline
\end{tabular}

\begin{tabular}{|l|l|l|l|l}
\hline 64 & 175 & 114 & 112 & 481 \\
\hline 100 & 85 & 150 & 98 & 453 \\
\hline
\end{tabular}

\begin{tabular}{l|l|l|l|l}
\hline 8 & 105 & 78 & 56 & 400 \\
\hline
\end{tabular}

\begin{tabular}{|l|l|l|l}
\hline 64 & 72 & 42 & 376 \\
\hline
\end{tabular}

\begin{tabular}{|l|l|l|l|l|}
\hline & 125 & 150 & 133 & 487 \\
\hline & 65 & 12 & 35 & 261 \\
\hline
\end{tabular}

\begin{tabular}{l|l|l|l|l} 
& & 12 & 35 & 261 \\
\hline
\end{tabular}

\begin{tabular}{|c|c|}
160 & 126 \\
Safety and Crime
\end{tabular}

Police protection

Vigilante protection at night \begin{tabular}{|l|l|l|l|l|l|l|}
\multicolumn{1}{|c|}{ Safety and Crime } \\
\hline
\end{tabular}

\begin{tabular}{l|l|l}
\hline & 182 & 491 \\
\hline
\end{tabular}

0.783

\begin{tabular}{|l|l|l|l|}
\hline $6^{\text {th }}$ & $35^{\text {th }}$ & N \\
\hline $1^{\text {st }}$ & $2^{\text {nd }}$ & MI \\
\hline $8^{\text {th }}$ & $44^{\text {th }}$ & SI
\end{tabular}

0.559

\begin{tabular}{|l|l|l}
\hline $11^{\text {th }}$ & $48^{\text {th }}$ & SI \\
\hline $4^{\text {th }}$ & $19^{\text {th }}$ & VI
\end{tabular}

Safety from crime

Safety from accident

Property safety

\begin{tabular}{l|l|l|l|l|l|l|l|l|} 
SC2 & 4 & 14 & 24 & 32 & 80 & 144 & 175 & 473 \\
\hline
\end{tabular}

\begin{tabular}{l|l|}
\hline 91 & 0.762 \\
\hline & 0.734 \\
\hline
\end{tabular}

$5^{\text {th }}$

\begin{tabular}{|l|l|}
\hline $26^{\text {th }}$ & I \\
\hline 54 th & NI \\
\hline $42^{\text {nd }}$ & N \\
\hline $44^{\text {h }}$ & SI
\end{tabular}

\begin{tabular}{|l|l|l|l|l|l|l|l|l|l|l}
$\mathrm{SC} 3$ & 2 & 4 & 12 & 36 & 100 & 150 & 210 & 514 & 0.798
\end{tabular}

\begin{tabular}{|l|l|l|l|l|l|l|l|l|l} 
SC4 & 0 & 2 & 9 & 40 & 125 & 114 & 238 & 528 & 0.82
\end{tabular}

Fire brigade service available

SC5

Street light

\begin{tabular}{l|l|l|l|l|l|l|l|l|} 
SC6 & 8 & 12 & 39 & 80 & 45 & 114 & 119 & 417
\end{tabular}

0.803

\begin{tabular}{ll}
0.648 \\
\hline 0.623
\end{tabular}

\begin{tabular}{|l|l|l|l|l|l|l|l} 
SC7 & 15 & 18 & 39 & 48 & 40 & 24 \\
\multicolumn{6}{c|}{ Functional Environment }
\end{tabular}

Distance to town center

Distance to work place

Distance to School

Distance to Hospital

Distance to shopping center

Distance to Market

\begin{tabular}{|l|l|l|}
\hline 217 & 401 & 0.623 \\
\hline
\end{tabular}

\begin{tabular}{|l|l|}
$8^{\text {th }}$ & $44^{\text {th }}$ \\
\hline $3^{\text {rd }}$ & $17^{\text {th }}$ \\
\hline
\end{tabular}

\begin{tabular}{l|l|l|l}
96 & 98 & 463 & 0.719 \\
\hline
\end{tabular}

\begin{tabular}{|l|l|l|l|l|l|l|l|l|l} 
FE2 & 2 & 6 & 12 & 80 & 170 & 96 & 98 & 463 & 0.719 \\
\hline
\end{tabular}

FE3

\begin{tabular}{|l|l|l|l|l|l|l|l|}
0 & 6 & 15 & 52 & 145 & 156 & 112 & 486 \\
\hline
\end{tabular}

\begin{tabular}{l|l|l|l|l|l|l|l|l|} 
FE4 & 2 & 8 & 15 & 44 & 105 & 168 & 147 & 489 \\
\hline
\end{tabular}

FE5

FE6

Distance to Bus Station/ Motor park $\quad$ FE7

\begin{tabular}{|l|l}
\hline Distance to public Library & FE8 \\
\hline
\end{tabular}

Distance to Mosque / Church

Distance to play area

Nearness to green space

Availability of Public transport

Distance to Police station

Distance to Fire station

Access to Water supply

Access to Electricity/Power supply

Nearness to food court
NOTE: NI=Not important, LI=Less Importance, SI=Slightly Importance, N=Neutral, I=Important, VI=Very Important,

\begin{tabular}{|l|l|l|l|l|l|l|l|l} 
FE8 & 19 & 18 & 75 & 56 & 40 & 72 & 35 & 315
\end{tabular}

\begin{tabular}{|l|l|l|l|l|l|l|l|l|l} 
FE9 & 0 & 2 & 24 & 32 & 90 & 180 & 189 & 517
\end{tabular}

\begin{tabular}{l|l|l|l|l|l|l|l|l|l} 
FE10 & 12 & 18 & 51 & 108 & 90 & 12 & 49 & 340
\end{tabular}

\begin{tabular}{|l|l|l|l|l|l|l|l|l} 
FE10 & 12 & 18 & 51 & 108 & 90 & 12 & 49 & 340 \\
\hline FE11 & 9 & 32 & 60 & 60 & 110 & 30 & 35 & 336
\end{tabular}

\begin{tabular}{|l|l|l|l|l|l|l|l|l} 
FE12 & 3 & 2 & 24 & 56 & 145 & 132 & 105 & 467 \\
\hline FE13 & 6 & 6 & 30 & 64 & 150 & 114 & 56 & 426
\end{tabular}

\begin{tabular}{l|l|l|l|l|l|l|l|l|l} 
FE13 & 6 & 6 & 30 & 64 & 150 & 114 & 56 & 426
\end{tabular}

\begin{tabular}{|l|l|l|l|l|l|l|l|l|} 
FE14 & 5 & 14 & 54 & 56 & 80 & 114 & 91 & 414
\end{tabular}

\begin{tabular}{|l|l|l|l|l|l|l|l|l} 
FE15 & 3 & 10 & 6 & 24 & 50 & 162 & 273 & 528
\end{tabular}

\begin{tabular}{l|l|l|l|l|l|l|l|l} 
FE16 & 1 & 0 & 6 & 40 & 70 & 150 & 280 & 547 \\
\hline FE17 & 5 & 8 & 39 & 88 & 125 & 72 & 77 & 414
\end{tabular}

\begin{tabular}{|l|l}
\hline & 0.755 \\
\hline & 0.759 \\
\hline 0.626 \\
\hline 0.675 \\
\hline 0.629 \\
\hline 0.489 \\
\hline 0.803 \\
\hline 0.528 \\
\hline & 0.522 \\
\hline 0.725 \\
\hline & 0.66 \\
\hline 0.643 \\
\hline & 0.82 \\
\hline & 0.84 \\
\hline & 0.643 \\
\hline
\end{tabular}

\begin{tabular}{|l|l}
$14^{\text {th }}$ \\
$12^{\text {th }}$
\end{tabular}

\begin{tabular}{l|l}
\hline $44^{\text {th }}$ & SI \\
\hline $17^{\text {th }}$ & VI \\
\hline
\end{tabular}

\begin{tabular}{|l|l}
\hline $55^{\text {th }}$ & VI \\
\hline $52^{\text {nd }}$ & NI \\
\hline $14^{\text {h }}$ & LI
\end{tabular}

\begin{tabular}{l|l|l}
$2^{\text {nd }}$ & $14^{\text {th }}$ & VI \\
\hline
\end{tabular}

$\mathrm{MI}=$ Most Important and RII=Relative Important Index

\begin{tabular}{|c|c|c|}
\hline $4^{\text {th }}$ & $15^{\text {th }}$ & VI \\
\hline $5^{\text {th }}$ & $21^{\mathrm{st}}$ & VI \\
\hline $3^{\text {rd }}$ & $12^{\text {th }}$ & MI \\
\hline $1^{\mathrm{st}}$ & $6^{\text {th }}$ & MI \\
\hline $2^{\text {nd }}$ & $10^{\text {th }}$ & MI \\
\hline $6^{\text {th }}$ & $34^{\text {th }}$ & $\mathrm{N}$ \\
\hline $7^{\text {th }}$ & $41^{\mathrm{st}}$ & $\mathrm{N}$ \\
\hline $8^{\text {th }}$ & $25^{\text {th }}$ & I \\
\hline $6^{\text {th }}$ & $22^{\text {nd }}$ & VI \\
\hline $5^{\text {th }}$ & $18^{\text {th }}$ & VI \\
\hline $4^{\text {th }}$ & $16^{\text {th }}$ & VI \\
\hline $14^{\text {th }}$ & $40^{\text {th }}$ & $\mathrm{N}$ \\
\hline $9^{\text {th }}$ & $32^{\text {nd }}$ & I \\
\hline $13^{\text {th }}$ & $39^{\text {th }}$ & $\mathrm{N}$ \\
\hline $17^{\text {th }}$ & $53^{\text {rd }}$ & LI \\
\hline $3^{\text {rd }}$ & $10^{\text {th }}$ & MI \\
\hline $15^{\text {th }}$ & $50^{\text {th }}$ & LI \\
\hline $16^{\text {th }}$ & $51^{\mathrm{st}}$ & LI \\
\hline $7^{\text {th }}$ & $23^{\text {rd }}$ & I \\
\hline $10^{\text {th }}$ & $33^{\text {rd }}$ & $\mathrm{N}$ \\
\hline $11^{\text {th }}$ & $35^{\text {th }}$ & $\mathrm{N}$ \\
\hline $2^{\text {nd }}$ & $6^{\text {th }}$ & $\mathrm{MI}$ \\
\hline $1^{\text {st }}$ & $3^{\text {rd }}$ & MI \\
\hline $11^{\text {th }}$ & $35^{\text {th }}$ & $\mathrm{N}$ \\
\hline
\end{tabular}


Table 2: Top ten (10) most important public low-cost housing attributes considered by the Jigawa State low-cost housing residents

\begin{tabular}{|l|c|l|c|c|}
\hline \multicolumn{1}{|c|}{ Attributes } & Code & \multicolumn{1}{c|}{ Attribute } & RII & Rank \\
\hline Neighbors' friendliness & SE3 & Social Environment-related & 0.859 & $1^{\text {st }}$ \\
\hline Masjid (Mosque)/ Church & PE3 & Physical Environment-related & 0.852 & $2^{\text {nd }}$ \\
\hline Access to Electricity/ Power supply & FE16 & Functional Environment-related & 0.849 & $3^{\text {rd }}$ \\
\hline Trust your neighbors? & SE5 & Social Environment-related & 0.837 & $4^{\text {th }}$ \\
\hline The number of Toilet & DUF6 & Dwelling features unit-related & 0.821 & $5^{\text {th }}$ \\
\hline Safety from accident & SC4 & Safety and Crime-related & 0.819 & $6^{\text {th }}$ \\
\hline Access to Water supply & FE15 & Functional Environment-related & 0.82 & $6^{\text {th }}$ \\
\hline The number of Bedroom & DUF3 & Dwelling features unit-related & 0.817 & $8^{\text {th }}$ \\
\hline Neighborhood helpful? & SE4 & Social Environment-related & 0.814 & $9^{\text {th }}$ \\
\hline Property safety & SC5 & Safety and Crime-related & 0.803 & $10^{\text {th }}$ \\
\hline Distance to Mosque / Church & FE9 & Functional Environment-related & 0.803 & $10^{\text {th }}$ \\
\hline
\end{tabular}

\section{CONCLUSION}

A The study revealed the general housing design of all public low-cost housing estates in Jigawa State, as either one or two bed-room housing unit, toilet/ (sometimes separated from bathroom), main door/entrance, windows, party wall (open spaces above ceiling level across all the housing units), close proximity of two bed-room's doors, verandah, open court yard and shared facilities like toilets system, ceiling roofing and wall boundary. Residents emphasized that, the housing design does not ensure privacy of the residents if compared to culture of Jigawa State people where they value privacy as the most important aspect in their life style. This is because most of the housing units lack fence or wall demarcation which they provide maximum privacy as encouraged by Hausa/Muslims' culture. The qualitative aspect results identified some of the housing designs attributes that affected the family's visual privacy as explained by the residents during individual interview. Some of these were the designs of position and location of some attributes such as toilet, doors, windows etc. which were positioned and located in such as a way that family inside the house are exposed to the visitors, strangers and passerby. This conditions have negative impact on the residents' subjective well-being.

In addition, the quantitative result assessed fifty five (55) public low-cost housing attributes distributed across five (5) main residential dimensions. These dimensions (dwelling unit features, social environment factors, physical environment factors, functional environment factors and safety and crime indicators) were found to be relevant to this study as they contained some attributes that were ranked as the most important to the residents. Apart from 12 most important attributes, 10 very important attributes and 10 important attributes as discussed earlier, the study also revealed 10 neutral attributes as ranked by the residents, among them are; size of the kitchen, parking area, size of drying area, street light, distances to shopping center, motor park, fire station etc.

Moreover, the residents of public low-cost housing preferred the housing design that will ensure privacy of their family in term of; provision of wall demarcation; more number of bedrooms, toilets and the position of main entrance should not face directly to the main street/road. The residents also, found sharing of toilets system and common roofing as part of housing design that affect the well-being. Other public low-cost housing attributes that perceived and ranked as the most important to them are; Masjid, social interaction, neighbors' friendliness and helpful. Therefore, future construction of public low-cost housing in Jigawa State should incorporate these attributes/items in order to improve the well-being of the residents.

\section{REFERENCES}

1. O. J. Adegoke. Effects of valuation variance and inaccuracy on Nigerian commercial property market: An emperical study. Journal of Property Investment and Finance. 2016 vol. 34(3), 276-292.

2. K. Al-Kodmany. Residential visual privacy: traditional and modern architecture and urban design. Journal Urban Design 1999 vol. 4(3), 283-311.

3. W. e. Alaghbari, A. Salim, K. Dola \& A. Abdullah Abang Ali. Developing affordable housing design for low income in Sana'a, Yemen. International Journal of Housing Markets and Analysis, 2011. Vol. 4(1), 84-98. doi:10.1108/17538271111111857

4. R. Asiyanbola, B. Raji \& G. Shaibu. Urban liveability in Nigeria- A pilot study of Ago- Iwoye and Ijebu-Igbo in Ogun State. Journal of Environmental Science and Engineering. 2012 pp. 1203-1213.

5. A. Ayoola \& D. Amole. The Value of Housing among the poor in Ilesa, Osun State Nigeria. Architecture Research 2014. Vol. 4(1A), 45-54. doi:10.5923/s.arch.201401.06

6. A. S. Bahammam. Architectural Patterns of Privacy in Saudi Arabian Housing. Unpublished Master of Architecture 1987. McGill University, Montreal.

7. H. A. Basiru, M. R. Yacob, A. Radam \& L. AbdManaf. Design-Attributes Relative Importance Index (DARII) Analysis for Improve Solid Waste Collection Services among Households in Kano Metropolis, North-Western, Nigeria. IOSR Journal of Humanities and Social Science. 2017. Vol. 22(04), 104-111. doi:10.9790/0837-220405104111.

8. A. Bekleyen \& N. Dalkiliç. The influence of climate and privacy on indigenous courtyard houses in Diyarbakır. Tur. Sci. Res. Essays. 2011 vol. 6(4), 908-922.

9. I. Dankani. Affordable Housing Provision in Kano North Western Nigeria: The Imperative for the Creation of Sustainable City. International Journal of Management and Social Sciences Research 2013. Vol. 2(8), 189-198. 
10. A. Delgado \& F. D. Troyer. Housing preferences for affordable social housing projects in Guayaquil, Ecuador. International Journal of Housing Markets and Analysis, 2017. Vol. 10(1), 112-139, doi: 10.1108/IJHMA-02-2016-0017.

11. G. Fadairo \& A. O. Olotuah. Low-Cost Housing for the Urban Poor in Akure, Nigeria Materials and Techniques of Construction. Journal of Environment and Earth Science, 2013. Vol. 3(9), 1-10.

12. B. S. Hakim. Arabic-Islamic Cities: Building and Planning Principles. London: KPI, 1986.

13. E. Heathcote. The Meaning of Home London: Frances Lincoln Limited, 2012.

14. E. O. Ibem, E. B. Aduwo \& O. Uwakonye. Adequacy of incremental construction strategy for housing low-income urban residents in Ogun State, Nigeria. Built Environment Project and Asset Management, 2012. Vol. 2(2), 182-194. doi:10.1108/20441241211280918.

15. E. O. Ibem \& O. O. Amole. Evaluation of Public Housing Programmes in Nigeria A Theoretical and Conceptual Approach. The Built \& Human Environment Review, 2010. Vol. 3(1), 88-117.

16. J. Ife \& F. Tesoriero. Community development: Community-based alternatives in an age of globalization (3 ed.). French Forest: Pearson Longman, 2006.

17. Y. Jabareen. Culture and Housing Preferences in a Developing City. Environment and Behavior, 2016. Vol. 37(1), 134-146. doi:10.1177/0013916504267640.

18. S. J. T. Jansen. The Impact of socio-economic characteristics, objective housing quality and preference on residential satisfaction. Delt, Netherland, 2012.

19. F. Khozaei, T. Ramayah, A. S. Hassan \& L. Surienty. "Sense of attachment to place and fulfilled preferences, the mediating role of housing satisfaction". Property Management, 2012. Vol. 30(3), 292-310.

20. C. Li, L. Sun \& P. Jones. Liveability of High-rise Housing Estates A Resident-centered High-Rise Residential Environment Evaluation in Tianjin, China. Paper presented at the 48th ISOCARP Congress 2012, China.

21. R. Linton. The cultural background of personality. NewYork: Appleton-Century-Crofts, 1945.

22. M. Lukuman, I. Sipan, F. Raji \& O. S. Aderemi. Sustainable livable housing: A review of what traditional urban areas residents find important. International Journal of Built Environment and Sustainability, 2017. Vol. 4(3). doi:10.11113/ijbes.v4.n3.212.

23. O. O. Makinde. Housing delivery system, need and demand. Environment, Development and Sustainability, 2014a. Vol. 16(1), 49-69. doi:10.1007/s10668-013-9474-9.

24. O. O. Makinde. Influences of socio-cultural experiences on residents' satisfaction in Ikorodu low-cost housing estate, Lagos state. International Journal of Sustainable Building Technology and Urban Development, 2014. Vol. 5(3), 205-221. doi:10.1080/2093761X.2014.927810.

25. M. A. Mohit \& A. M. M. Al-Khanbashi Raja. Residential Satisfaction Concept, Theories and Empirical Studies. Planning Malaysia Journal, 2014. Vol. 12(3). doi:10.21837/pmjournal.v12.i3.131.

26. M. A. Mohit \& S. A. Iyanda. City Liveability and Housing in Nigeria: A Case Study of Low-income Housing in Niger State. Procedia - Social and Behavioral Sciences, 2015. Vol. 2(1), 1-13.

27. M. A. Mohit \& S. A. Iyanda. Low-Income Housing in Nigeria: A liveability investigation. Asian Journal of Quality of Life, 2017. Vol. 2(6), 43. doi:10.21834/ajqol.v2i6.45

28. H. Mortada. Traditional Islamic principles of built environment. New York: Routledge Curzon, 2011.

29. Z. Muhammad, F. Johar, S. Sabri \& Z. U. Jonathan. A review of Housing Provision and the Challenges of Sustainable Housing Delivery in the Federal Capital Territory Abuja, Nigeria. Jurnal Teknologi (Sciences \& Engineering), 2015. Vol. 1(1), 23-31.

30. A. R. Noriza. Residential satisfaction in private low - cost housing in the urban area: A case study of the Klang Valley, Malaysia. Istanbul, Turkey, 2010.

31. A. E. Olajuyigbe, S. Osakpolor \& S. A. Adegboyega. Assessment of Quality of Life Using Geographical Information System Approach for Poverty Alleviation Decision-Making. International Journal of Sustainable Land Use and Urban Planning, 2013. Vol. 1(1), 1-20.

32. L. Olayiwola, O. Adeleye \& A. Jiboye. Effect of Socio-Cultural factors on Housing Quality in Osogbo, Nigeria. Paper presented at the CIB W107 Construction in Developing Countries International Symposium "Construction in developing Economies: New Issues and Challenges", Santiago, Chile, 2006.
33. A. O. Olotuah. Accessibility of Low-Income Earners to Public Housing in Ado-Ekiti, Nigeria. Civil and Environmental Research, 2015. Vol. 7(7), 1-7.

34. Z. Othman, R. Aird \& L. Buys. Privacy, modesty, hospitality, and the design of Muslim homes: A literature review. Frontiers of Architectural Research, 2015. Vol. 4, 12-23. doi:10.1016/j.foar.2014.12.001.

35. R. U. Pandey, Y. K. Garg \& A. Bharat. Understanding Dependency of Livability on Socio-Economic and Demographic Parameters. International Journal of Humanities and Social Sciences, 2014. Vol. 3(1), 61-68.

36. A. Rapoport. Theory, culture and housing. Housing, Theory and Society, 2001. Vol. 17(1), 145-165.

37. A. Rapoport. On the Cultural Responsiveness of Architecture. Journal of Architectural Education, 2014. Vol. 41(1), 10-15. doi:10.1080/10464883.1987.10758460.

38. J. Ritchie \& J. Lewis. Qualitative Rearch Practice: A guide for social science students and researchers. London: Sage, 2003.

39. B. L. Tanko, F. Abdullah \& Z. M. Ramly. Stakeholders Assessment of Constraints to Project Delvery in the Nigerian Construction Industry. International Journal of Built Environment and Sustainability, 2017. Vol. 4(1).

40. T. Teck- Hong. Neighborhood preferences of house buyers: the case of Klang Valley, Malaysia. International Journal of Housing Markets and Analysis, 2011. Vol. 4(1), 58-69. doi:10.1108/17538271111111839.

41. G. Tipple, D. Korboe, G. Garrod \& K. Willis. Housing Supply in Ghana: a study of Accra, Kumasi and Berekum. Progress in Planning, 1999. Vol. 51(4), 255-324.

42. J. F. C. Turner. Housing By People Towards Autonomy in Building Environments. London: Marion Boyars Publishers Ltd, 1976.

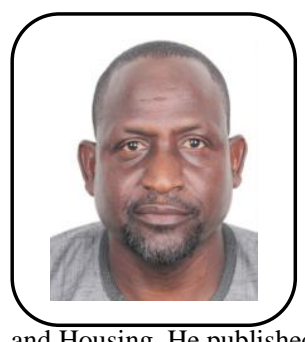

\section{AUTHORS PROFILE}

Sunusi Bashari, Currently PhD. Student in the field of Housing Studies at University Putra Malaysia. $\mathrm{He}$ is a Nigerian working with Jigawa State College of Education, Gumel as a lecturer. He specialized in the issues related to Geography such as Land Resources Development, Water Resource Management and Housing. He published many articles on Water Quality and Housing.

Professor Dr. Ahamad Hariza Hashim, Department of Resource Management and Consumer Studies Faculty of Human Ecology University Putra Malaysia. Currently, Dean Faculty of Human Ecology, UPM and specialized in the field (s) Housing and Environment. He published 64 research articles in top rated journals and published 3 books. He also graduated 6 doctors and several masters' degrees.

Professor Dr. Asnarulkhadi Abu Samah, Department of Social and Development Sciences Faculty of Human Ecology University Putra Malaysia. Currently, Director Institute for Social Science Studies, University Putra Malaysia. He is life member of several international organizations such as International Association for Community Development, Delopment Persatuan Sains Social Malaysia and Pertuan Ekonomi Pengguna dan Keluarga Malaysia. He received Academic and Non-Academic awards such as Dean Fellowship Award and Best Author Award respectively. He published several articles journals and graduated many doctorates students.

Associate Professor Dr. Nobaya BT Ahmad, Department of Social and Development Sciences Faculty of Human Ecology University Putra Malaysia. Currently, Head of Department (Department of Social and Development Sciences) Malaysia. She specialized in Town and Regional Planning. She has published a lot of articles on issues related to Housing, Building, and Town and Regional Planning. She produced many postgraduate students. 